\title{
Health and social problems following illicit drug use among males experiencing incarceration in prison; a cross sectional study on single centre experience
}

\author{
Darshana ILAN ${ }^{1}$, Ruben $\mathbf{R}^{2}$, Wijesinghe $C \mathbf{J}^{1}$ \\ ${ }^{1}$ Department of Community Medicine, Faculty of Medicine, University of Ruhuna, Galle, Sri Lanka. \\ ${ }^{2}$ Psychiatry unit, Teaching Hospital, Karapitiya, Sri Lanka.
}

Correspondence: Dr. I. L.A. Nuwan Darshana

e-mail: ilandare@gmail.com

(D) https://orcid.org/0000-0002-1289-9426

Submitted on 23.04.2021 and accepted for publication on 03.06.2021

\begin{abstract}
Introduction: Illicit drug use is a growing public health problem which affects health and social wellbeing of drug users. A significant proportion of prison admissions is illicit drug-related in many countries including Sri Lanka. This study was conducted to describe the possible health and social problems linked with illicit drug use among males experiencing incarceration in prison, Galle.

Methods: A cross-sectional study was conducted among 254 males experiencing incarceration with history of illicit drug use in prison, Galle. An interviewer assisted, self-administered questionnaire was used to assess the presence of known health and social problems linked with illicit drug use which were identified through literature. Associated factors for presence of health and social problems following illicit drug use were assessed using Chi square test at 0.05 significance level.

Results: Drug-related prison admissions were reported among $79.1 \%$ of individuals and $57.1 \%$ of individuals were prison readmissions. Poly drug use (36.2\%) and drug dependence (56.7\%) was reported in significant proportion of males experiencing incarceration. Drug Abuse Screening test (DAST) 20 revealed that 35.4\% of individuals had higher level of problematic drug use. Health and social problems following illicit drug use were common among individuals experiencing incarceration and their presence was associated with poly drug use, drug dependence and problematic drug use ( $p<0.05$ for all).
\end{abstract}

Conclusion: Past illicit drug use and related health and social problems were common among inmates in prison, Galle, creating a considerable burden for the prison system of the country.

Key words: Health problems, illicit drug use, males experiencing incarceration, social problems.

\section{Introduction}

Illicit drugs are defined as psychoactive substances whose production, sale or long term use on regular basis for a non-medical purpose is prohibited with the prevailing legal system of a given country (1). Heroin, cannabis, cocaine, crystal meth, hallucinogens and psychotropic drugs etc. are illicit

drugs that are commonly found in Sri Lanka. Addiction or usage of these illicit drugs has become a significant problem in the country (2). It harms not only the people who take drugs, but also the people around them including children, families and the society (3). 
Illicit drug use can affect people at any age, from any background, rich or poor. It leads to many health and social problems. According to the World Drug Report, illicit drug use causes a variety of health and social consequences accounting for an increased global burden. A person who uses illicit drugs can come from all walks of life and many suffer from medical, psychological, occupational, financial, legal, family and social relationship problems. Conflicts due to neglecting responsibili-ties, negligence within family, problems with sexual relationships and engaging in illegal activities to purchase drugs were identified as issues with immediate family and social impact linked with illicit drug use. All of these problems render their addictive behaviour much more difficult to treat. Additionally, addiction increases the addict's risk to a wide variety of other illnesses affecting many systems of the body. These may come about due to the toxic effects of the drugs or as a result of the poor living and health habits that is normally associated with the lifestyle and behaviour of the addict. Furthermore, it causes significant burden for the economy of the country, mainly for health services and rehabilitation programmes $(2,4)$.

Prison population is considered as one of the most vulnerable groups among vulnerable populations to get addicted to illicit drugs (5). Although they deserve to be the focus of some health and social interventions according to existing evidence; generally less attention is given to this group across the globe (6). The situation is similar in Sri Lanka. Illicit drug use is a common problem among prison population (7-9) and drug related offences account for much of the prison admission $(8,9)$, making it a significant health and social concern. Yet, scant attention has been given to explore this problem in the local context. This paucity of data has further impeded the development and implementation of preventive and health promotion activities targeting illicit drug users including individuals experiencing incarceration. This study attempted to identify possible health and social problems linked with illicit drug use among males experiencing incarceration who had history of illicit drug use in prison Galle. The identification of these problems will help relevant authorities to take necessary actions for solving and preventing them, which would be beneficial for individuals experiencing incarceration themselves and other affected groups such as their families and immediate society.

\section{Methods}

A cross sectional study was conducted among a sample of 254 males experiencing incarceration and had history of illicit drug use in prison, Galle from February 2018 to January 2019. Random sample of 449 males experiencing incarceration was selected in initial stage of the study and they were screened using Drug Abuse Screening Test 20 (DAST 20) to identify individuals with history of illicit drug behaviour. Accordingly, among 449, 254 individuals were identified with history of illicit drug behaviour. According to prison statistics, majority of the prison admissions were male $(>94 \%)$ in prison Galle (9) and therefore only the male prison population was included for the study. The study sample included adult male prisoners who were convicted, remanded or who had appealed against the conviction, having history of illicit drug use and only those admitted within one year prior to data collection. After confirming eligibility, each study subject was approached through prison medical centre. The support of the prison medical officer was obtained for subject recruitment. Permission was obtained from the Commissioner General of Prison, Department of Prison, Ministry of Justice and Prison Reforms, Sri Lanka to recruit the subjects. Ethical approval for the study was obtained from the Ethical Review Committee of the Postgraduate Institute of Medicine, University of Colombo, Sri Lanka.

A pretested, interviewer-assisted, self-administered questionnaire with closed ended questions was used to assess health and social problems following illicit drug use in order to ensure a high response rate and accuracy of data divulged after obtaining informed written consent from the participants. ICD 10 symptom checklist for substance use disorder was used to identify those having drug dependence. DAST 20 was used to assess the problematic level of drug use. Possible health and social problems following illicit drug use that were identified through literature search were included in the questionnaire. This was assessed according to the individual perception. However, diagnosis of disease conditions which were obtained from 
study participants was confirmed using medical records available at prison medical centre whenever possible as no other method was available to ensure health problems following illicit drug use.

All data were collected by the principal investigator and privacy and confidentiality were strictly maintained. Data were coded and entered into an Epi Info $^{\mathrm{TM}}$ data sheet and transferred to a data base created using the Statistical Package for Social Sciences (SPSS) software (version 20). After cleaning the data set, frequency tables and other descriptive methods were applied to observe the behavior of different variables. DAST score was compared with the American Society of Addiction Medicine (ASAM) Placement Criteria to assess problematic level of illicit drug use; drug users with DAST scores compatible with level III and IV of ASAM criteria were considered as having high problematic level and drug users with DAST scores corresponding to level I and II were considered as having low problematic level. Associated factors for presence of health and social problems linked with illicit drug use were assessed with drug dependence status, problematic level of drug use, poly-drug use and prison readmission status using Chi square test. Level of significance was considered as 0.05 .

\section{Results}

\section{Sample Characteristics}

Nearly all the individuals (97.6\%) were resident in Galle district. Majority of individuals were Sinhalese (97.6\%), Buddhist (96.9\%) and less than 36 years old $(71.1 \%)$ with mean (SD) of 30.6 (7.6) years. Nearly three-fourth of sample had lower (less than GCE O/L) education level (75.6\%), were unskilled manual workers $(59.1 \%)$ and had satisfactory (more than 25,000 rupees) monthly income (71.3\%). Drug related prison admissions were reported among $79.1 \%$ of individuals and $57.1 \%$ of individuals were prison readmissions. Poly drug use $(36.2 \%)$ and drug dependence $(56.7 \%)$ was reported in significant proportions of males experiencing incarceration. DAST 20 revealed that $35.4 \%$ of individuals had higher level of problematic drug use while $64.6 \%$ had lower level according to the American Society of Addiction Medicine (ASAM) criteria.

\section{Health problems linked with illicit drug use before imprisonment}

Accident and injuries (23.2\%) and dental caries $(16.9 \%)$ were reported as common health problems following drug use among males experiencing incarceration in prison, Galle before imprisonment (Table 1). At least one health problem due to past illicit drug use was reported among $43.7 \%(n=111)$ of individuals. There were $41.7 \%$ with risky sexual behaviours among past illicit drug users, including 9.1\% with homosexual behavior. Further 13.7\% reported IV drug use.

Presence of at least one health or related problem due to illicit drug use was taken as presence of health problems due to past illicit drug use. Presence of health problems due to past illicit drug use was significantly associated with poly drug use, drug dependence and problematic drug use (Table 2). Individuals experiencing incarceration who had history of poly drug use $(p<0.001)$, drug dependence $(p<0.001)$ and having higher level of problematic drug use $(p<0.001)$ were more likely to have health problems following illicit drug use.

\section{Social problems linked with illicit drug use before imprisonment}

Legal problems $(72.8 \%)$, financial problems $(51.6 \%)$ and employment problems $(26.0 \%)$ were identified as common social problems among individuals experiencing incarceration in prison, Galle following illicit drug use before imprisonment (Table 3). At least one social problem following past illicit drug use was reported among $83.0 \%$ $(\mathrm{n}=211)$ of individuals experiencing incarceration.

Statistically significant associations for presence of social problems following illicit drug use were identified with poly drug use, drug dependence and problematic drug use (Table 4). Individuals experiencing incarceration, who had history of poly drug use $(p<0.001)$, drug dependence $(p<0.001)$ and high level of problematic drug use $(p=0.001)$ were more likely to have social problems following illicit drug use. Individuals experiencing incarceration who had previous prison admissions were not associated with presence of health or social problems. 
Table 1: Health-related problems linked with illicit drug use among males experiencing incarceration in prison, Galle $(n=254)$

\begin{tabular}{lcc}
\hline Health-related problems & \multicolumn{3}{c}{ Number (\%) * } \\
\hline Accidents / Injuries & 59 & $(23.2)$ \\
Dental carries & 43 & $(16.9)$ \\
Skin diseases & 23 & $(9.1)$ \\
Respiratory diseases (Asthma / COPD) & 21 & $(8.3)$ \\
Suicidal attempts & 13 & $(5.1)$ \\
Cardiovascular diseases & 11 & $(4.3)$ \\
Significant weight loss & 10 & $(3.9)$ \\
Sexual dysfunction & 6 & $(2.4)$ \\
Psychiatric disorders & 4 & $(1.6)$ \\
Blood borne viral infections & 3 & $(1.2)$ \\
Tuberculosis & 1 & $(0.4)$ \\
Sexually transmitted diseases & 1 & $(0.4)$ \\
\hline
\end{tabular}

* Percentages do not add up to $100 \%$ due to multiple responses

Table 2: Factors associated with presence of health problems following illicit drug use among males experiencing incarceration in prison, Galle $(n=254)$

\begin{tabular}{|c|c|c|c|c|c|}
\hline \multirow[t]{2}{*}{ Characteristics } & \multicolumn{4}{|c|}{ Presence of health problems } & \multirow[t]{2}{*}{$p$ value } \\
\hline & $\begin{array}{l}\text { Yes } \\
\text { Num }\end{array}$ & $\begin{array}{l}n=111) \\
\text { ber }(\%)\end{array}$ & $\begin{array}{l}\text { No }(n=143) \\
\text { Number }(\%)\end{array}$ & $\begin{array}{l}\text { Total } \\
\text { Number (\%) }\end{array}$ & \\
\hline \multicolumn{6}{|l|}{ Poly drug use } \\
\hline Yes & 58 & $(63.0)$ & $34(37.0)$ & $92(100)$ & $<0.001 *$ \\
\hline No & 53 & $(32.7)$ & $109(67.3)$ & $162(100)$ & \\
\hline \multicolumn{6}{|c|}{ Drug dependence } \\
\hline Yes & 83 & $(57.6)$ & $61(42.4)$ & $144(100)$ & $<0.001$ * \\
\hline No & 28 & $(25.4)$ & $82(74.6)$ & $110 \quad(100)$ & \\
\hline \multicolumn{6}{|c|}{ Problematic level of drug use } \\
\hline Low & 53 & $(32.3)$ & $111(67.7)$ & $164(100)$ & $<0.001 *$ \\
\hline High & 58 & $(64.4)$ & $32(35.6)$ & $90 \quad(100)$ & \\
\hline \multicolumn{6}{|c|}{ Readmissions to prison } \\
\hline Yes & 69 & $(47.6)$ & $76(52.4)$ & $145(100)$ & 0.150 \\
\hline No & 42 & $(38.5)$ & $67(61.5)$ & $109(100)$ & \\
\hline
\end{tabular}

$* p$ value is significant at 0.001 
Table 3: Social problems linked with illicit drug use among males experiencing incarceration in prison, Galle $(\mathrm{n}=254)$

\begin{tabular}{lrc}
\hline Social Problem & \multicolumn{3}{c}{ Number $(\%) *$} \\
\hline Legal problems & 185 & $(72.8)$ \\
Financial problems & 131 & $(51.6)$ \\
Employment problems & 66 & $(26.0)$ \\
Disputes in community & 60 & $(23.6)$ \\
Disrupted family relationships & 54 & $(21.3)$ \\
Conflicts with neighbours & 37 & $(14.6)$ \\
Domestic violence & 11 & $(4.3)$ \\
Negligence by the family & 4 & $(1.6)$ \\
\hline
\end{tabular}

* Percentages do not add up to $100 \%$ due to multiple responses

Table 4: Factors associated with presence of social problems following illicit drug use among males experiencing incarceration in prison, Galle $(n=254)$

\begin{tabular}{|c|c|c|c|c|}
\hline \multirow[t]{2}{*}{ Characteristics } & \multicolumn{3}{|c|}{ Presence of social problems } & \multirow[t]{2}{*}{$p$ value } \\
\hline & $\begin{array}{l}\text { Yes }(\mathrm{n}=211) \\
\text { Number }(\%)\end{array}$ & $\begin{array}{l}\text { No }(n=43) \\
\text { Number }(\%)\end{array}$ & $\begin{array}{l}\text { Total } \\
\text { Number (\%) }\end{array}$ & \\
\hline \multicolumn{5}{|l|}{ Poly drug use } \\
\hline Yes & $89(96.7)$ & $3 \quad(3.3)$ & $92(100)$ & $<0.001 *$ \\
\hline No & $122(75.3)$ & $40(24.7)$ & $162(100)$ & \\
\hline \multicolumn{5}{|l|}{ Drug dependence } \\
\hline Yes & $134(93.1)$ & $10 \quad(6.9)$ & $144(100)$ & $<0.001 *$ \\
\hline No & $77(70.0)$ & $33(30.0)$ & $110(100)$ & \\
\hline \multicolumn{5}{|c|}{ Problematic level of drug use } \\
\hline Low & $12777.4)$ & $37(22.6)$ & $164(100)$ & $0.001 * *$ \\
\hline High & $84(93.3)$ & $6 \quad(6.7)$ & $90(100)$ & \\
\hline \multicolumn{5}{|c|}{ Readmission to prison } \\
\hline Yes & $124(85.5)$ & $21(14.5)$ & $145(100)$ & 0.230 \\
\hline No & $87(79.8)$ & $22(20.2)$ & $109(100)$ & \\
\hline
\end{tabular}

$* p$ value is significant at $0.001 ; \quad * * p$ value is significant at 0.05 


\section{Discussion}

In this study, outcomes of past illicit drug use were assessed under health and social problems known to be related to their use. This study identified accidents and injuries, dental caries, respiratory diseases and skin diseases as common health problems which are comparable with those in the literature. However, health problems were not assessed in depth in a descriptive manner and the participants were only asked to select the problems experienced by them from a given problem list that had been prepared according to evidence available in the literature. Although 'other' option was included to record anything other than those in the list, response rate was negligible for that option. Therefore, it could be anticipated that information bias can affect this part of the results. However, a comprehensive list of health problems identified through several sources was included in the questionnaire to minimise this possibility. Although study subjects were recruited through the prison medical centre, there was a difficulty in accessing prison medical records which are maintained by prison medical officers at prison for verification of reported problems due to ethical issues. Therefore, only the past medical records (e.g. clinic books and diagnosis cards of prison inmates) were used to retrieve data.

In the literature, many studies have found that accident and injuries following illicit drug use are very common in many countries (10-12) comparable to our study finding. This is mainly occurred due to impulsive behaviour following its illicit drug use. It has been reported that many illicit drugs cause dental carries due to chemicals in them (13). It was not uncommon in this study too and dental caries were reported by $16.9 \%$ of illicit drug users. Similar to our findings, respiratory diseases are not uncommon among drug users. Tuberculosis, bronchial asthma, chronic obstructive pulmonary diseases were identified as common respiratory problems comparable to our study findings in the literature $(14,15)$. Skin diseases were prevalent among the inmates of our study. An association has been observed between skin diseases and illicit drug use; dermatitis, skin and soft tissue infections were identified as common dermatological conditions and many of them are due to poor hygiene of drug users and the practice of injecting drugs (16).
Other adverse health consequences were reported in low prevalence in our study were not in concordance with the literature. According to a study done by Dissabandara et al. (2009), 11.2\% reported a history of sexually transmitted diseases (STD). In contrast, it was $0.4 \%$ in this study sample. Blood borne viral infections were reported by $1.2 \%$. However, there were $41.7 \%$ with risky sexual behaviours among past illicit drug users and $13.7 \%$ reported IV drug use. Although STD and blood borne viral infections were reported in lower percentages, considering the high prevalence of risk behaviours it will be worthwhile to screen prison inmates for STD. Psychiatric disorders were reported among $29 \%$ of prison inmates in a study conducted in Australia (17). In comparison, a very low percentage $(1.6 \%)$ was observed in the present study. This low prevalence of health problems in the present study could be due to under-reporting of health problems resulting from the inadequate appraisal in the study. Combining self-reported information with a thorough clinical examination and analysis of past medical records would have been useful in minimising this error.

When considering, adverse social consequences linked with illicit drug use, legal problems, financial problems, employment problems, disputes in community, disrupted family relationships and disruption of academic activities were identified as common social problems. According to available evidence in Sri Lanka, disruption of family relationships, employment problems, legal problems, negligence within family and disruption of sexual relationships are common social problems among drug users (18). Interestingly, domestic violence was not reported in their study. However, apart from above mentioned social problems, domestic violence was reported among $4.3 \%$ of drug users in our study.

Domestic violence was reported in a similar study conducted in the Netherlands in relation to cannabis and cocaine use (19). Moreover, financial problems, legal problems and disruption of family relationships were similarly reported in another study done in India (20). Most of the drug users try to keep their problems due to illicit drug use under cover due to fear of discrimination. This further affects their problematic level of drug use (21). These findings were comparable with the literature (20-22). 
Prison inmates, who had a history of poly drug use, addicted to illicit drugs and had a higher level of problematic drug use were more likely to have health or social problems linked with illicit drug use. Drug users who used multiple drugs, addicted to drugs and had higher problematic level drug use are usually more vulnerable to adverse consequences following drug use as all of these factors lead them to more exposure to illicit drugs. Therefore, unsurprisingly they were more likely to have health or social problems linked with illicit drug use.

In this study, new problems related to behaviour of illicit drug use could not be identified except those already identified through literature. There is a lack of data on health problems and social problems related to illicit drug use even in global and regional literature. This emphasises the need for more research studies for further evaluation of health and social problems related to illicit drug use.

\section{Limitations}

There were a few limitations in this study. Several precautions had to be taken during the designing stage as the study included a vulnerable population. It was ensured that the responses provided by the participants will allow them to be identified neither within their own local community nor the larger national or academic community to which the findings of the study will be presented to. Hence, prison officials' help was not obtained for study subject recruitment. Every study subject was approached through the prison medical centre and the support from prison medical officer was obtained for subject recruitment. A self-administered format was used to optimise the response rate as the questionnaire addressed sensitive issues. Further, legal status of prisoners (convicted, remanded or appealed against the conviction) was not questioned to avoid misinterpretation by the participants that it would affect any services or decisions they received or would receive in future and any adverse consequences of them. As outcomes of past illicit drug use were assessed under health and social problems known to be related following drug use, it limited the comprehensiveness of assessment. Study had to rely on individual perception of possible health and social problems following drug use. As the research addressed sensitive issues, some questions were omitted to avoid ethical issues, thereby. Furthermore, the study population was limited to the prison, Galle limiting the generalisability of findings as described elsewhere in this paper. In addition, the crosssectional nature of the study may have masked the temporal relationship between past illicit drug use and associated problems. The possibility of recall bias and bias due to 'socially desirable responses' cannot be overlooked, although every step was taken to minimize it. However, study subjects were recruited using pre-determined inclusion and exclusion criteria to avoid possible biases. Prison inmates who were imprisoned more than one year to minimise recall bias and those who were mentally unsound were excluded from the study to minimize information bias. Study subjects were supported by principal investigator during the process with any clarifications if required to minimize information bias.

In summary, it was identified that health problems and social problems due to past illicit drug use among prison inmates were common and they were associated with poly drug use, drug dependence and problematic drug use. As there is a lack of data in relation to health and social problems linked with past illicit drug use among prison inmates in Sri Lanka, result of this study will be helpful for policy makers and practitioners to develop preventive strategies for prison inmates with a history of illicit drug use. Identification of prison inmates who had a past illicit drug use will be required at the time of prison admission, which will be required to refer them to proper rehabilitation care. These measures will be beneficial to reduce burden on prison system of the country due to illicit drug use. Hence findings of this study can be used in national development of the country.

\section{Acknowledgements}

We wish to acknowledge, The Commissioner General of Prisons, Department of Prisons, Ministry of Justice and Prison Reforms, Sri Lanka for granting permission for data collection, the Superintendent of Prison, Galle and administrative staff of the prison, Galle for the support given during data collection, two medical officers of the 
medical centre of the Prison, Galle for the support given during subject recruitment and data collection for the study and all the participants in the study including those participated for the pretest for their cooperation for the study, and the staff members of the Department of Community Medicine, Faculty of Medicine, University of Ruhuna for the support given during the study.

Manuscript does not contain any individual data in any form (including any individual details, images or videos). Therefore, consent for publication was not considered.

\section{References}

1. Lexicon of alcohol and drug term. Geneva: World Health Organization; 1994.

2. Hand Book on Drug Abuse Information 2017. Rajagiriya: Research Division, 2017.

3. The Impact of Substance Use Disorders on Families and Children: From Theory to Practice. Social Work in Public Health. 2013; 28(0): 194-205. DOI: 10.1080/19371918.2013.759005.

4. Substance abuse and rehabilitation; responding to the global burden of diseases attributable to substance abuse. Substance Abuse and Rehabilitation. 2010; 1: 5-11. DOI: $10.2147 /$ SAR.S14898.

5. UNDOC. Drug use and its health consequences 2016 [cited 2019 04.01.2019]. Available from: http://www.unodc.org/wdr2016/en/drug-use.html

6. Lafferty L, Treloar C, Butler T, Guthrie J, Chambers GM. Unlocking dimensions of social capital in the prison setting. Health \& Justice. 2016; 4(1): 9 .

7. NDDCB. Hand Book on Drug Abuse Information 2017 Rajagiriya: National Dangerous Drug Control Board Research Division; 2017.

8. PNB. Annual Report 2017. Sri Lanka Police, 2017.

9. Statistic Division of Department of Prisons. Prison Statistics of Sri Lanka 2018 [cited 2019 02.01.2019]. Available from: http://www.prisons.gov.lk/Statistics/ Statistics-2018.pdf.

10. Vitale S, Van de Mheen D. Illicit drug use and injuries: a review of emergency room studies. Drug and Alcohol Dependence. 2006; 82 (1):1-9.
11. Woratanarat $\mathrm{P}$, Ingsathit $\mathrm{A}$, Suriyawongpaisal $\mathrm{P}$, Rattanasiri S, Chatchaipun $\mathrm{P}$, Wattayakorn $\mathrm{K}$, et al. Alcohol, illicit and non-illicit psychoactive drug use and road traffic injury in Thailand: a case-control study. Accident Analysis \& Prevention. 2009; 41(3): 651-7.

12. Single E, Robson L, Rehm J, Xie X, Xi X. Morbidity and mortality attributable to alcohol, tobacco, and illicit drug use in Canada. American Journal of Public Health. 1999; 89(3): 385-90.

13. Abdollahi M, Radfar M. A review of drug-induced oral reactions. J Contemp Dent Pract. 2003; 4(1): 10-31.

14. Mégarbane B, Chevillard L. The large spectrum of pulmonary complications following illicit drug use: features and mechanisms. Chemico-Biological Interactions. 2013; 206(3): 444-51.

15. Han B, Gfroerer JC, Colliver JD. Associations between duration of illicit drug use and health conditions: results from the 2005-2007 national surveys on drug use and health. Annals of Epidemiology. 2010; 20(4): 289-97.

16. Irish C, Maxwell R, Dancox M, Brown P, Trotter C, Verne J, et al. Skin and soft tissue infections and vascular disease among drug users, England. Emerging Infectious Diseases. 2007; 13(10): 151.

17. Butler T, Indig D, Allnutt S, Mamoon H. Co-occurring mental illness and substance use disorder among Australian prisoners. Drug and alcohol review. 2011; 30(2): 188-94.

18. Sathya Herath, Atul Ambekar. Rapid Assessment of Drug Use Patterns (RADUP) in Sri Lanka, 2018.

19. Choenni V, Hammink A, van de Mheen D. Association between substance use and the perpetration of family violence in industrialiszed countries: a systematic review. Trauma, Violence, \& Abuse. 2017; 18(1): 37-50.

20. Mattoo SK, Nebhinani N, Kumar BA, Basu D, Kulhara P. Family burden with substance dependence: a study from India. The Indian Journal of Medical Research. 2013; 137(4): 704.

21. Ahern J, Stuber J, Galea S. Stigma, discrimination and the health of illicit drug users. Drug and Alcohol Dependence. 2007; 88(2-3): 188-96.

22. Boardman JD, Finch BK, Ellison CG, Williams DR, Jackson JS. Neighborhood disadvantage, stress, and drug use among adults. Journal of Health and Social Behaviour. 2001; 42(2): 151-165. 